\title{
miR-143 suppresses the proliferation of NSCLC cells by inhibiting the epidermal growth factor receptor
}

\author{
HONG-BO ZHANG* , LI-CHAO SUN*, LAN LING, LU-HONG CONG and RUI LIAN \\ Department of Emergency Medicine, China-Japan Friendship Hospital, Beijing 100029, P.R. China
}

Received March 10, 2015; Accepted April 8, 2016

DOI: $10.3892 /$ etm.2016.3555

\begin{abstract}
MicroRNAs (miRs) regulate the proliferation and metastasis of numerous cancer cell types. It was previously reported that miR-143 levels were downregulated in non-small cell lung cancer (NSCLC) tissues and cell lines, and that the migration and invasion of NSCLC cells was inhibited upon suppression of cell proliferation and colony formation by the upregulation of miR-143. Epidermal growth factor receptor (EGFR), which is a vital factor in the promotion of cancer cell proliferation and has been investigated as a potential focus in cancer therapy, has been reported to be a possible target of miR-143. The present study aimed to investigate the role of miR-143 in NSCLC using NSCLC cell lines and primary cells from NSCLC patients. NSCLC cells were co-transfected with EGFR and miR-143, and the mRNA and protein expression of EGFR were analyzed. Furthermore, the activity of the transfected cancer cells with regard to colony formation, migration, invasion and apoptosis were evaluated. The levels of miR-143 were decreased in the NSCLC cell lines and primary cells from patients with NSCLC compared with the controls. Following transfection with miR-143, the ability of NSCLC cells to proliferate, form colonies, migrate and invade was inhibited. Similarly, knockdown of EGFR led to the suppression of NSCLC cell proliferation. The mRNA and protein expression levels of EGFR were significantly reduced following miR-143 overexpression, and the level of miR-143 was inversely correlated with that of EGFR in NSCLC cells. The results of the present study demonstrated that miR-143 was able to suppress NSCLC cell proliferation and invasion by inhibiting the effects of EGFR, suggesting that EGFR may be considered a potential target for NSCLC therapy.
\end{abstract}

Correspondence to: Dr Hong-Bo Zhang, Department of Emergency Medicine, China-Japan Friendship Hospital, 2 Yinghuayuan East Street, Beijing 100029, P.R. China

E-mail: zhongbzh@126.com

*Contributed equally

Key words: microRNA-143, epidermal growth factor receptor, non-small cell lung cancer

\section{Introduction}

Lung cancer is the most common cause of cancer-associated mortality worldwide, and the incidence of lung cancer is rapidly increasing in developing countries (1). Lung cancer incidence rates are approximately twice as high in developed countries (61/100,000 males and 19/100,000 females) compared with developing countries $(29 / 100,000$ males and 10/100,000 females) $(2,3)$. Of the types of lung cancer, non-small cell lung cancer (NSCLC) accounted for $80 \%$ of all lung cancer cases (4). The primary types of NSCLC are adenocarcinoma (including bronchioloalveolar carcinoma), which accounts for $32-40 \%$ of NSCLC cases, squamous NSCLC, which accounts for $25-30 \%$ of cases, and large cell NSCLC, which account for 8-16\% of cases (5). Despite recent advances in the diagnosis and chemotherapeutic and targeted treatment of NSCLC, including immunotherapy, such as epidermal growth factor receptor (EGFR) targeted treatment, insulin-like growth factor 1 receptor or EML4-ALK fusion protein interference (6), the overall survival rate of NSCLC patients remains low (5-year survival rate of $15 \%$ ) and the recurrence rate of NSCLC remains high, even with early diagnosis (7). The poor prognosis of NSCLC may be due to the relatively limited understanding of its underlying etiology, in addition to the late presentation and heterogeneity of lung cancer (8). Therefore, elucidation of the molecular mechanisms underlying NSCLC tumor metastasis, including signaling pathways, associated receptors and/or binding sites, is urgently required.

MicroRNAs (miRs) have been revealed to function in the regulation of gene expression and have important roles in a wide range of physiological and pathological processes $(9,10)$. The majority of miRs negatively regulate the expression of their target genes by binding to the 3'-untranslated regions (3'-UTRs) of mRNA, leading to mRNA degradation or translational suppression $(11,12)$. In numerous biological processes, including cell proliferation, differentiation, migration and apoptosis, miRs are involved in regulating the expression of multiple target genes (13-15).

Aberrant miR expression has been associated with numerous types of cancer, and it has been suggested that miRs may act as inhibitors of oncogenes or as tumor suppressors (16-18). Various miRs, including miR-183, miR-21 and miR-155, have been shown to promote the development of NSCLC (19). Conversely, miR-99a, miR-340 and 
miR-223, were reported to function as tumor suppressors in NSCLC $(20,21)$. The survival rate of a cecal ligation and puncture-induced sepsis in a mouse model was shown to be improved by TLR3-activated mesenchymal stromal cells, whereas the effectiveness of this therapy was reduced by overexpression of miR-143 (22). Furthermore, miR-143 was demonstrated to upregulate the mRNA expression levels of absent in melanoma 2 and apoptosis-associated speck-like protein containing a CARD in a Jurkat cell line (23), and it was suggested that miR-143 may be used as a novel diagnostic biomarker for NSCLC (24). However, the function of miR-143 in NSCLC remains poorly understood. EGFR has been observed to be an important factor in the promotion of cancer cell proliferation (25). Numerous studies have been performed on EGFR as a targeted therapy for NSCLC (26). EGFR has been observed to be directly regulated by miR-128b (27). As a functional factor of cell proliferation, EGFR was considered to be a potential target of miR-143. Therefore, the present study aimed to investigate the role of miR-143 in NSCLC, particularly its ability to regulate the processes of cancer cell migration, invasion, proliferation and apoptosis. Furthermore, the EGFR was analyzed as a potential target of miR-143 in NSCLC cells.

\section{Materials and methods}

Patients and cell lines. NSCLC tissue samples, human NSCLC primary cells and matched normal tissues (normal tissue extracted adjacent to the NSCLC tissue in the same patient) were obtained from 35 patients at the Department of Respiratory Medicine of the China-Japan Friendship Hospital (Beijing, China) between January 2014 and January 2015. Written informed consent was obtained from all patients and the present study was approved by the Medical Ethics Committee of the China-Japan Friendship Hospital. The clinicopathological information for the patients is summarized in Table I. All tissue samples were stored in liquid nitrogen for subsequent processing. A549, H520 and H460 NSCLC cell lines, in addition to the $16 \mathrm{HBE}$ normal lung bronchus epithelial cell line, were obtained from the ATCC (Manassas, VA, USA). These cell lines differed in applications. The expression levels of miR-143 were investigated in the tissue samples, the $16 \mathrm{HBE}$ normal lung epithelial cell line and the three NSCLC cell lines (A549, H520 and H460). The suppressive effect of miR-143 on the proliferation, migration and invasion of NSCLC were studied in A549 cells. The potential target effects of EGFR were also studied in A549 cells. All cell lines were cultured separately in Dulbecco's modified Eagle's medium (DMEM) supplemented with 10\% fetal bovine serum (FBS) and streptomycin/penicillin at $37^{\circ} \mathrm{C}$ in a humidified atmosphere containing $5 \% \mathrm{CO}_{2}$. Upon reaching $80 \%$ confluence, the NSCLC cells were transfected with miR-143 or control mimics (Yoshimitsu Biotechnology Co., Ltd., Shanghai, China) using Lipofectamine 2000 (Invitrogen; Thermo Fisher Scientific, Inc., Waltham, MA, USA), according to the manufacturer's protocol.

RNA extraction and quantitative PCR ( $q P C R)$. The expression levels of miR-143 in 35 pairs of NSCLC tissue samples and their matched normal tissue samples were determined.
Firstly, the tissues were sectioned into $2 \times 2 \times 2 \mathrm{~mm}$ sections and all the tissues were homogenized. Then, total RNA was extracted from the tissue homogenate using the mirVana ${ }^{\mathrm{TM}}$ miRNA Isolation kit (Ambion; Thermo Fisher Scientific, Inc.), according to the manufacturer's instructions. Thirdly, miR was extracted with a microRNA Fast Extraction kit (Spin column; Signalway Antibody Co., College Park, MD, USA) and detected with an All in One ${ }^{\mathrm{TM}}$ miRNA RT-qPCR Detection kit (GeneCopoeia, Inc., Rockville, MD, USA). The purity and quality of the RNA were verified by measuring the absorbance at 260 and $280 \mathrm{~nm}$ (A260 and A280) on the NanoDrop 2000 spectrophotometer (Thermo Fisher Scientific, Inc.). An A260/A280 ratio of 2.0 was considered an acceptable quality.

miR was extracted from the total RNA using a microRNA Fast Extraction kit (Spin-column; Signalway Antibody Co., College Park, MD, USA) and detected with an All-in-One ${ }^{\mathrm{TM}}$ miRNA qRT-PCR Detection kit (GeneCopoeia, Inc., Rockville, MD, USA) with SYBR Green reagents (Sigma-Aldrich, St. Louis, MO, USA), according to the manufacturer's protocol. The primers used to amplify miR-143 were purchased from Guangzhou RiboBio Co., Ltd (sequences unknown). Amplification was conducted with the following thermocycling conditions: $95^{\circ} \mathrm{C}$ for $20 \mathrm{sec}$ followed by 50 cycles at $95^{\circ} \mathrm{C}$ for $10 \mathrm{sec}$ and $55^{\circ} \mathrm{C}$ for $20 \mathrm{sec}$. Following EGFR mRNA amplification from the total RNA, the mRNA was reverse transcribed into cDNA using AMV reverse transcriptase (Promega Corporation, Madison, WI, USA). The expression level of EGFR mRNA was assessed using the SYBR Premix Ex Taq ${ }^{\mathrm{TM}}$ II (Tli RNase H Plus) kit (Takara Bio, Inc., Otsu, Japan) according to the manufacturer's protocol with the following primers (Sangon Biotech Co. Ltd., Shanghai, China): Forward, 5'-TGTCCAACGAATGGGCCTAA-3' and reverse, 5'-TGGCTTTCGGAGATGTTGCT-3'. The PCR thermocycling conditions were as follows: $50^{\circ} \mathrm{C}$ for $10 \mathrm{sec}$ and $95^{\circ} \mathrm{C}$ for $10 \mathrm{~min}$, followed by 46 cycles at $95^{\circ} \mathrm{C}$ for $15 \mathrm{sec}$ and $60^{\circ} \mathrm{C}$ for $1 \mathrm{~min}$. EGFR and miR-143 expression were normalized to glyceraldehyde 3-phosphate dehydrogenase (GAPDH). The primers used to detect GAPDH expression were as follows: GAPDH forward, 5'-AATGACCCCTTCATTGAC-3', and reverse, 5'-TCCACGACGTACTCAGCGC-3'. The expression levels were quantified using the $2^{-\Delta \Delta \mathrm{Cq}}$ method (28).

Cell survival assays. A549 cell proliferation was assessed using a BrdU Cell Proliferation ELISA kit (EMD Millipore, Billerica, MA, USA). Briefly, 6×10³ A549 cells/well were cultured in 96 -well plates in DMEM for $24 \mathrm{~h}$ at $37^{\circ} \mathrm{C}$, then $10 \mathrm{ml} \mathrm{BrdU}$ reagent was added to each well and the plates were incubated for $1.5 \mathrm{~h}$ at $37^{\circ} \mathrm{C}$. Absorbance at $450 \mathrm{~nm}$ was measured using a microplate reader.

Colony formation assay. In order to assess colony formation, 500 A549 cells/well were seeded into 6-well plates $24 \mathrm{~h}$ following transfection and cultured in DMEM for 2 weeks at $37^{\circ} \mathrm{C}$. The culture medium was renewed after 3 days, following which the cells were fixed with methanol, stained with $0.5 \%$ crystal violet for $20 \mathrm{~min}$ and visible colonies were counted using a microscope (DM600; Leica Microsystems $\mathrm{GmbH}$, Wetzlar, Germany). Triplicate wells were measured for each sample. 
Flow cytometry. Cell apoptosis was analyzed by flow cytometry and fluorescence-activated cell sorting was employed to determine the fraction of apoptotic cells. The NSCLC A549 cell lines were treated with $50 \mu \mathrm{M}$ quercetin (SigmaAldrich) for 1, 2 or 4 days in order to trigger apoptosis, after which the cells $\left(1 \times 10^{6}\right)$ were fixed with $80 \%$ ethanol, stained with propidium iodide solution and analyzed using the FACSCalibur ${ }^{\mathrm{TM}}$ flow cytometer with CellQuest software (version 7.5.3; BD Biosciences, San Jose, CA, USA). Another apoptosis assay was conducted by dual-laser flow cytometry. Briefly, following treatment with $50 \mu \mathrm{M}$ quercetin, the cells were stained with $1 \mu \mathrm{g} / \mathrm{ml}$ Hoechst stain and $1 \mu \mathrm{g} / \mathrm{ml} 7$-aminoactinomycin D. The co-stained cells were then analyzed with a FACSCalibur flow cytometer.

Migration and invasion. A549 cell migration and invasion were assessed using Transwell chambers. Briefly, A549 cells were transfected with miR-143 and then incubated for $24 \mathrm{~h}$ at $37^{\circ} \mathrm{C}$ in DMEM. The transfected cells $\left(5 \times 10^{4}\right)$ were seeded into the upper chamber containing DMEM, following which DMEM supplemented with $10 \%$ FBS was added to the lower chamber to function as a chemoattractant. The chambers were incubated at $37^{\circ} \mathrm{C}$ in $5 \% \mathrm{CO}_{2}$ for $16 \mathrm{~h}$, followed by removal of the cells remaining on the upper surface of the chamber. Cells that had migrated to the bottom surface were washed twice with cold phosphate-buffered saline, fixed in methanol and stained with $0.1 \%$ crystal violet. Stained cells were counted under a microscope. All assays were performed in triplicate.

Western blotting. The cells were treated with $50 \mu \mathrm{M}$ quercetin for 2 days and subsequently lysed using lysis buffer $(0.2 \mathrm{M}$ ethylenediaminetetraacetic acid, $0.05 \mathrm{M}$ Tris-HCl, $\mathrm{pH} 8.0$, $5 \%$ Triton $\mathrm{X}-100$ ) for $30 \mathrm{~min}$ on ice to obtain total protein. In order to validate the assays, A549 cells were treated with two different concentrations of quercetin $(25$ or $50 \mu \mathrm{M})$. Protein concentration was determined using a bicinchoninic acid assay. The proteins $(2 \mu \mathrm{l} /$ well $)$ were separated by electrophoresis on a $10 \%$ sodium disulphide-polyacrylamide gel and transferred onto nitrocellulose membranes for incubation with rabbit monoclonal anti-EGFR (1:5,000; cat. no. EP38Y; Abcam, Cambridge, UK) and rabbit polyclonal anti-GAPDH (loading control; cat. no. ab9585; 1:2,500; Abcam) primary antibodies overnight at $4^{\circ} \mathrm{C}$. Subsequently, the membranes were incubated with horseradish peroxidase-conjugated goat anti-rabbit immunoglobulin $\mathrm{G}$ secondary antibodies (cat. no. ab6721; 1:20,000; Abcam) for $1 \mathrm{~h}$ at room temperature. Protein bands were detected with the WEST-ZOL (Plus) Western Blot Detection System (Intron Biotechnology, Inc., Seongnam, Korea) and the relative intensity was calculated by normalizing to the GAPDH loading control using ImagePro Plus 6.0 (Media Cybernetics, Inc., Rockville, MD, USA). Experiments were performed in triplicate.

Plasmids and luciferase activity assays. miR-143, miR-143 inhibitor, control mimic and control inhibitors were obtained from Yoshimitsu Biotechnology Co., Ltd. EGFR short hairpin RNA (shRNA) was obtained from Guangzhou RiboBio Co., Ltd. (Guangzhou, China) and used as an inhibitor of EGFR expression. For the expression of EGFR, the coding sequence of EGFR was amplified using the following primers: Forward,
Table I. Clinicopathological data.

\begin{tabular}{lrcc}
\hline Variable & Low & High & P-value \\
\hline Age, years & 13 & 7 & $0.234^{\mathrm{a}}$ \\
$\geq 60$ & 9 & 6 & \\
$<60$ & & & $0.173^{\mathrm{b}}$ \\
Gender & 12 & 9 & \\
$\quad$ Male & 8 & 6 & \\
Female & 9 & & \\
Size of tumor & 13 & 6 & \\
$>3$ cm & & & \\
$\leq 3$ cm & 11 & 8 & \\
Histological type & 10 & 6 & $0.528^{\mathrm{a}}$ \\
Adenocarcinoma & & & \\
Squamous cancer & 15 & 7 & \\
Lymph node status & 10 & 3 & \\
Metastasis & & & \\
No metastasis & & & \\
\hline
\end{tabular}

${ }^{\mathrm{a}} \chi^{2}$ test; ${ }^{\mathrm{b}}$ Mann-Whitney $\mathrm{U}$ test. Low, low miR-143 $\left(<2.3 \times 10^{-2}\right)$; high, high miR-143 $\left(\geq 2.3 \times 10^{-2}\right)$.

5'-ACCTGCGTGAAGAAGTGTCC-3', and reverse, 5'-CGT TACACACTTTGCGGCAAGG-3'. The coding sequence was subsequently cloned into PMD19T (Takara Bio, Inc.) by polymerase chain reaction (PCR), according to the manufacturer's instructions.

Luciferase activity assays were performed to assess the suppressive effect of miR-143 on EGFR expression in HEK293 cells, which was a model cell line specifically used to study the transfection of functional genes (ATCC). Briefly, to construct a luciferase expression vector containing part of the EGFR 3'-UTR, the wild-type (WT) 568-886 fragment of EGFR mRNA, encoding the potential miR-143 binding sites at position 2436-3121, was amplified using the following primers: Forward, 5'-ACCTGCGTGAAGAAGTGTCC-3'; and reverse, 5'-CGTTACACACTTTGCGGCAAGG-3'. The PCR thermocycling conditions were as follows: $50^{\circ} \mathrm{C}$ for $10 \mathrm{sec}$ and $90^{\circ} \mathrm{C}$ for $10 \mathrm{~min}$, followed by 30 cycles at $90^{\circ} \mathrm{C}$ for $15 \mathrm{sec}$ and $55^{\circ} \mathrm{C}$ for $1 \mathrm{~min}$. Mutation of the EGFR $3^{\prime}$-UTR (Mut) was performed using the cobas ${ }^{\circledR}$ EGFR Mutation Test (Roche Molecular Diagnostics, Pleasanton, CA, USA). The resulting PCR fragment was inserted into the pGL3-Basic Vector (Promega Corporation, Madison, WI, USA) encoding the $\mathrm{Bam} \mathrm{HI/Sal} \mathrm{I} \mathrm{endonuclease} \mathrm{restriction} \mathrm{sites} \mathrm{according} \mathrm{to}$ the manufacturer's protocol. The ligation was performed with DNA Ligase (Takara Bio, Inc.). Subsequently, $80 \%$ confluent HEK293 cells were co-transfected with $100 \mathrm{ng}$ WT or Mut EGFR 3'-UTR and $80 \mathrm{nM}$ miR-143 or control mimics using Lipofectamine 2000. A proportion of the cells were alternatively transfected with 80 ng PMD19T control vector in order to monitor the transfection efficiency. miR-NC was applied as a non-targeting negative control. Furthermore, all cells were transfected with pRL-SV40 (Promega Corporation) as a control for normalization. Cells were harvested $48 \mathrm{~h}$ after transfection for subsequent analyses. A549 cells were 
transfected with miR-143, control mimic miR-143 inhibitor and control inhibitor (Shanghai GenePharma Co., Ltd., Shanghai, China). A549 cells were transfected with either EGFR-targeted shRNA or non-targeted shRNA. The mRNA and protein expression levels of EGFR were detected by qPCR and western blotting as previously described. The viability, migration and invasion of A549 cells were also detected as previously described.

Statistical analysis. Data are presented as the mean \pm standard deviation. Student's t-test was performed, and $\chi^{2}$ and Mann-Whitney U tests were applied to analyze the clinicopathological information of patients using SPSS 16.0 software (SPSS, Inc., Chicago, IL, USA). P $<0.05$ was considered to indicate a statistically significant difference.

\section{Results}

miR-143 is downregulated in NSCLC tissues and cell lines. The expression levels of miR-143 were measured in 35 NSCLC tissue samples and their matched normal tissue samples using qPCR. The expression levels of miR-143 were markedly decreased in NSCLC tissues compared with the normal control tissues (Fig. 1A). The expression levels of miR-143 in three NSCLC cell lines were similarly determined, and miR-143 was significantly downregulated in the NSCLC cell lines compared with the 16HBE normal lung bronchus epithelial cell line (Fig. 1B). These results suggest that the progression of NSCLC may be associated with downregulation of miR-143.

miR-143 suppresses NSCLC cell proliferation. miR-143 was transfected into A549 NSCLC cells to investigate its effect on NSCLC cell proliferation using the BrdU cell proliferation assay. Successful transfection of the cells with miR-143 mimic was confirmed by qPCR (Fig. 2A). Compared with the corresponding controls, A549 cell proliferation was markedly suppressed by miR-143 overexpression (Fig. 2B). In addition, flow cytometry demonstrated that miR-143 overexpression was able to induce the apoptosis of A549 cells (Fig. 2C). Furthermore, a colony formation assay was performed to assess whether varying the expression level of miR-143 results in A549 cell cycle arrest or cell death, since either of these would result in a reduction in colony number. The ability of A549 cells to form colonies was significantly inhibited following the overexpression of miR-143 (Fig. 2D). These results suggest that miR-143 is able to suppress NSCLC cell growth.

miR-143 suppresses NSCLC cell migration and invasion. Transwell assays were used to assess the migratory and invasive behaviour of A549 cells transfected with miR-143 or control mimics. Migration (Fig. 3A) and invasion (Fig. 3B) were markedly inhibited in A549 cells transfected with miR-143 compared with cells transfected with control mimics. These data suggest that NSCLC cell death and injury may be induced by miR-143.

EGFR is a potential target of miR-143. Luciferase activity assays were used to investigate the suppressive effect of

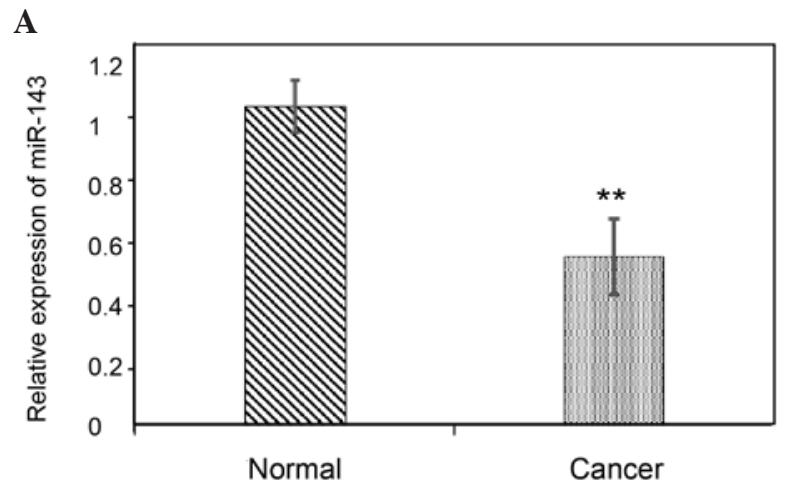

B

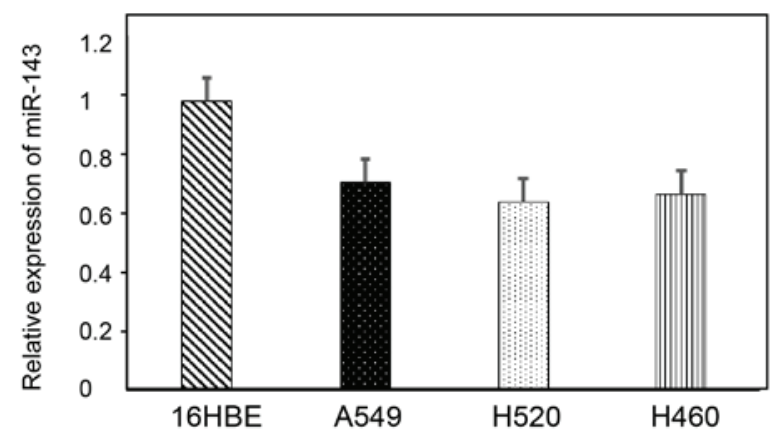

Figure 1. Comparison of miR-143 expression levels between normal cells and NSCLC cancerous tissues and cell lines. (A) The expression levels of miR-143 in 35 pairs of NSCLC tissues and their matched normal tissues were determined by quantitative polymerase chain reaction. (B) The expression levels of miR-143 in the 16HBE normal lung epithelial cell line and three NSCLC cell lines (A549, H520 and H460). Data are presented as the mean \pm standard deviation. ${ }^{*} \mathrm{P}<0.05,{ }^{* *} \mathrm{P}<0.01$ vs. the normal tissues or $16 \mathrm{HBE}$ cell line. miR-143, microRNA-143; NSCLC, non-small cell lung cancer.

miR-143 on EGFR expression in HEK293 cells. The luciferase activity of the WT EGFR was markedly inhibited in HEK293 cells transfected with miR-143 compared with the cells transfected with control mimics (Fig. 4A). miR-143 was used to determine the effects of miR-143 on EGFR. miR-143 inhibitor was used to determine the effects on EGFR following miR-143 inhibition. Control mimic was used as a negative control of miR-143 control. The length of the mimic was similar to miR-143 although lacked a known function. Control inhibitor was used as a negative control of miR-143 inhibitor. Its length was similar to miR-143 inhibitor but lacked a known function. Furthermore, the mRNA and protein expression levels of EGFR were significantly reduced in HEK293 cells transfected with miR-143, as compared with cells transfected with the control mimic (Fig. 4B-D). These results suggest that miR-143 overexpression induces a reduction in EGFR mRNA, leading to a reduction in the levels of EGFR protein. Furthermore, the inverse correlation between the levels of miR-143 and EGFR suggested that EGFR may be a target of miR-143.

EGFR inhibition and miR-143 overexpression exert identical effects. A549 cells were transfected with EGFR-targeted shRNA or non-targeted control to investigate whether shRNA EGFR silencing exerts similar effects on NSCLC cells to the effects associated with miR-143 overexpression. Downregulation of the protein and mRNA expression levels of EGFR 
A

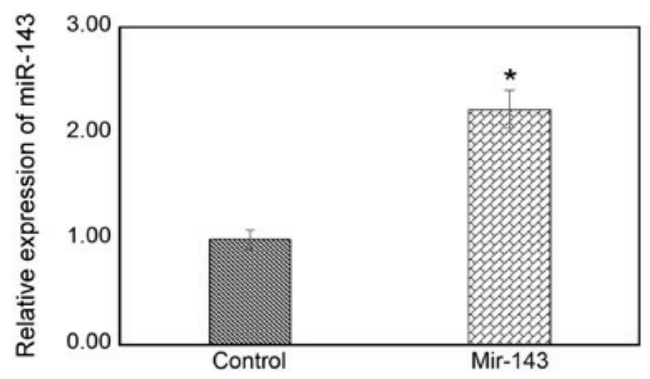

C

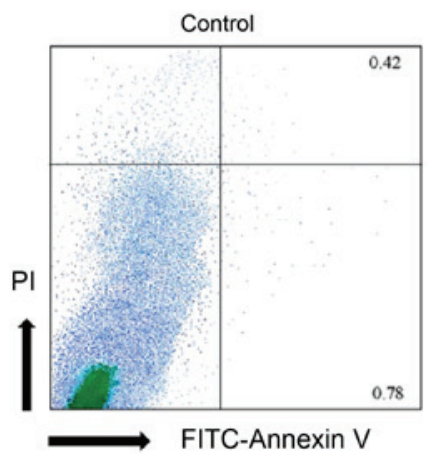

B

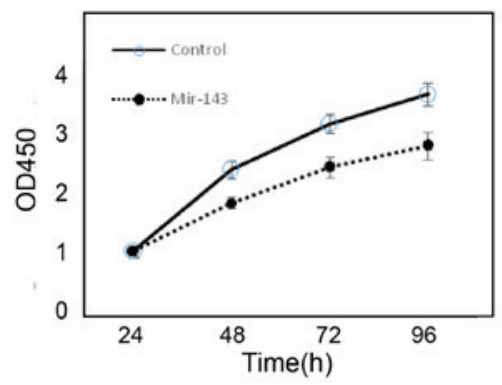

D

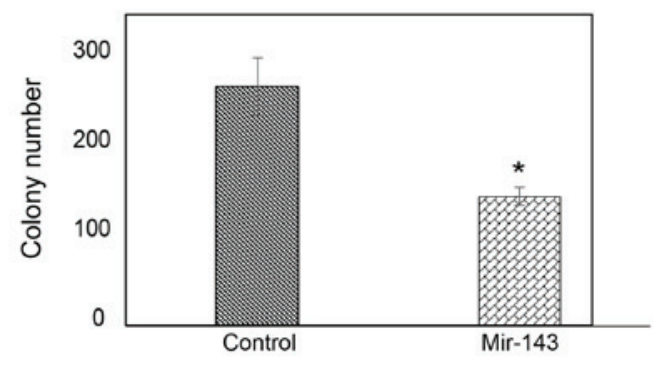

Figure 2. Suppressive effect of miR-143 on the proliferation of non-small cell lunger cancer cells. (A) Successful transfection of A549 cells with miR-143 was confirmed by quantitative polymerase chain reaction. (B) The proliferation of A549 cells transfected with miR-143 was significantly reduced compared with cells transfected with control mimics. (C) miR-143 overexpression induced the apoptosis of A549 cells, as determined by flow cytometry. (D) The colony forming ability of A549 cells transfected with miR-143 were significantly reduced compared with cells transfected with control mimics. Data are presented as the mean \pm standard deviation. ${ }^{*} \mathrm{P}<0.05,{ }^{* *} \mathrm{P}<0.01$ vs. the control. miR-143, microRNA-143; OD, optical density.

A

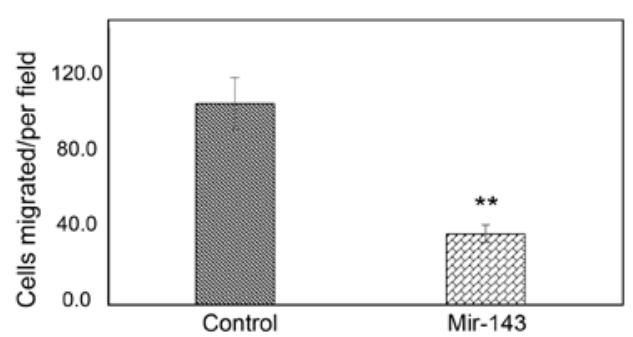

B

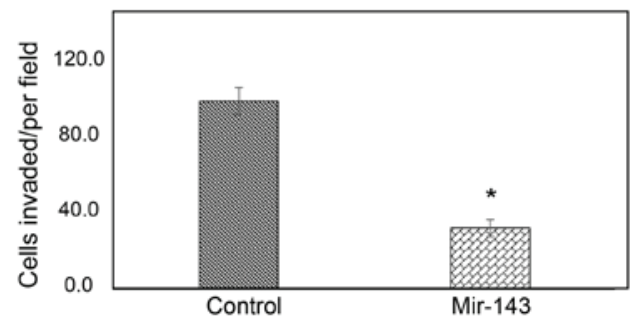

Figure 3. Suppressive effect of miR-143 on non-small cell lung cancer cell migration and invasion. The migration and invasion of A549 cells was assessed using a Transwell assay. The (A) migration and (B) invasion of A549 cells transfected with miR-143 were significantly reduced compared with the cells transfected with the control mimics. Data are presented as the mean \pm standard deviation. ${ }^{*} \mathrm{P}<0.05,{ }^{* *} \mathrm{P}<0.01$ vs. the control. miR-143, microRNA-143.

following transfection of A549 cells with EGFR shRNA was confirmed by western blotting (Fig. 5A and B) and qPCR (Fig. 5C). Notably, the inhibition of EGFR by shRNA reduced the proliferation, migration and invasion of A549 cells (Fig. 5D-F). These results suggest that the inhibitory effects of EGFR-targeted shRNA on EGFR are similar to those of miR-143 overexpression.

\section{Discussion}

miRs have been shown to have fundamental roles in numerous biological processes, including carcinogenesis, angiogenesis, programmed cell death, cell proliferation, invasion, migration and differentiation $(29,30)$. Previous studies have reported that miRs are associated with the onset and progression of various types of cancer, that miRs may act as tumor suppressors or oncogenes, and have implicated them in aberrations in the expression of key genes $(28,31)$. The diverse roles described for miRs have been elucidated by analyzing their biological synthesis and functions (32). Each miR is capable of regulating the expression of numerous genes, thus allowing them to affect multiple cellular signaling pathways simultaneously (33).

Increasingly, previous studies have focused on the inhibitory effects of miRs on cancer and tumors; cyclooxygenase-2 activity was demonstrated to be suppressed by miR-143, preventing gastric cancer growth and inducing the apoptosis of gastric cancer cells (34). Furthermore, miR-145 levels were enhanced by histone deacetylase inhibitors in a Burkitt lymphoma cell line, and the levels of miR-143 were markedly downregulated in samples from patients with Burkitt lymphoma (35). Low and high levels of miR-143 in cancer 
A

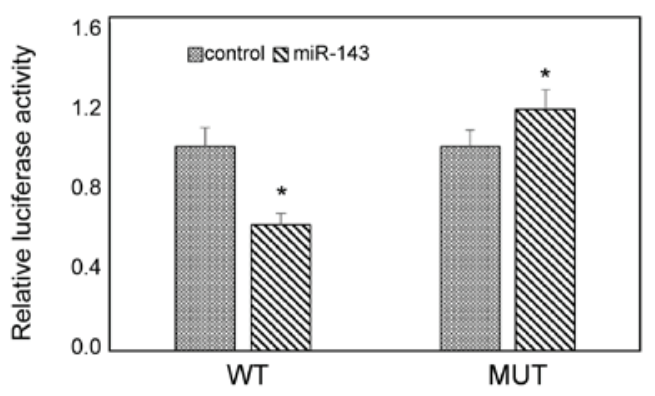

C

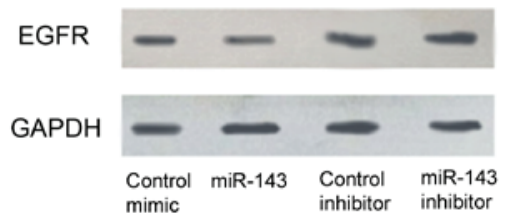

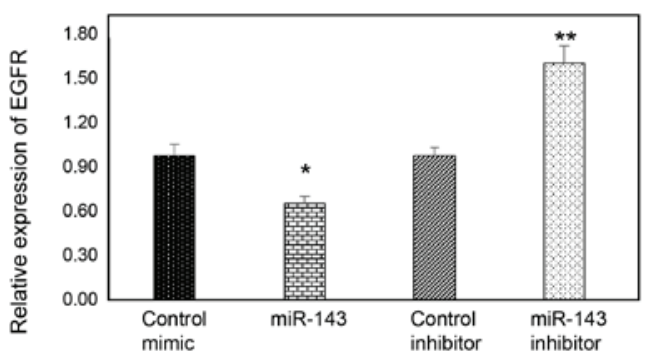

D

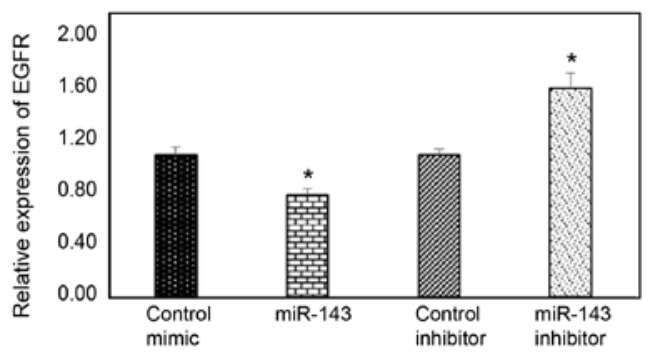

Figure 4. EGFR is a potential target of miR-143. (A) The inhibitory effects of miR-143 on luciferase activity in HEK293 cells co-transfected with $100 \mathrm{nM}$ WT or Mut EGFR 3'-untranslated region and miR-143 or negative control mimics. The (B) mRNA and (C and D) protein expression levels of EGFR in A549 cells transfected with miR-143 or control mimic and A549 cells transfected with miR-143 or control inhibitor, were detected by quantitative polymerase chain reaction and western blotting, respectively. GAPDH was used as an internal control. "P<0.05, ${ }^{* *} \mathrm{P}<0.01$ vs. the control. EGFR, epidermal growth factor receptor; miR-143, microRNA-143; WT, wild-type; Mut, mutant; GAPDH, glyceraldehyde 3-phosphate dehydrogenase; NC, normal control; shRNA, short hairpin RNA.

A

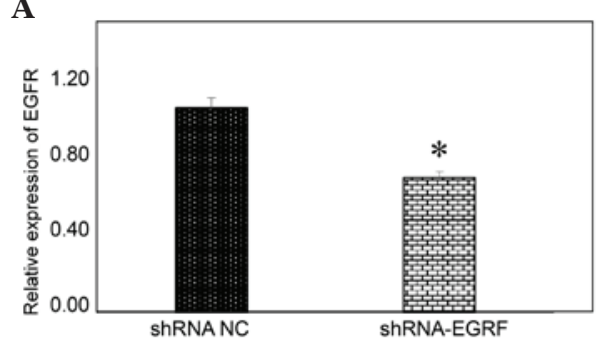

D

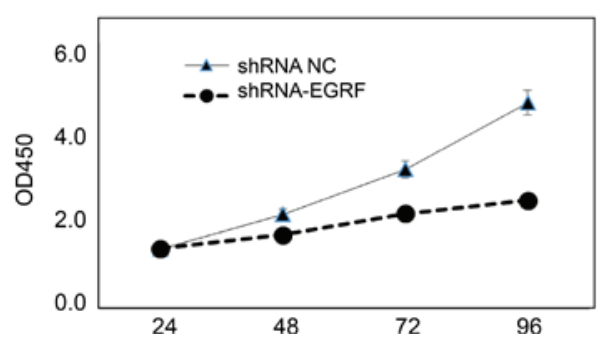

B

EGFR

GAPDH

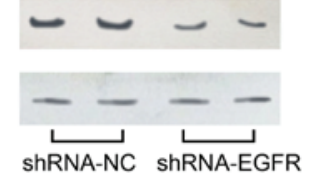

$\mathbf{E}$

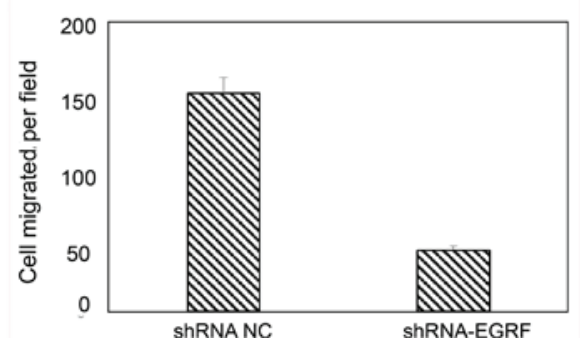

C

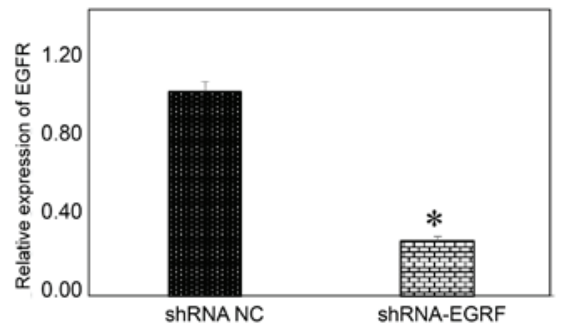

F

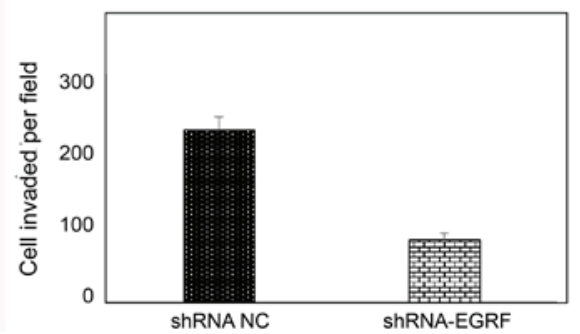

Figure 5. Similar effects were observed for EGFR inhibition and microRNA-143 overexpression. The (A) mRNA and (B and C) protein expression levels of EGFR were significantly reduced in the A549 cells transfected with EGFR shRNA compared with the cells transfected with the NC shRNA. The mRNA and protein expression levels of EGFR were detected by quantitative polymerase chain reaction and western blotting, respectively. The (D) viability, (E) migration and (F) invasion of A549 cells transfected with EGFR shRNA were significantly reduced, as compared with the cells transfected with the NC shRNA. Data are presented as the mean \pm standard deviation. "P $<0.05,{ }^{* *} \mathrm{P}<0.01$ vs. the shRNA NC. EGFR, epidermal growth factor receptor; shRNA, short hairpin RNA; NC, normal control; OD, optical density.

cells and normal cells, respectively, were associated with the differential expression of reporters and tumor necrosis factor- $\alpha$ (36). In addition, a previous study demonstrated that the expression of DNA methyltransferase $3 \mathrm{~A}$ was regulated by miR-143 in breast cancer cells (37), and it was reported that prostate cancer cell migration and invasion were enhanced following the loss of the tumor-suppressive miR-143/145 cluster due to alterations in the expression level of Golgi membrane protein 1 (38). Insulin activity, including insulinmediated phosphorylation of Akt and insulin-stimulate glucose uptake, was shown to be inhibited by epicardial adipose tissue-type 2 diabetes-mediated release of activin A, which may have occurred due to miR-143 activation in cardiomyocytes (39). Furthermore, the expression of miR-143 was 
affected by numerous factors associated with insulin sensitivity in a previous study (39).

EGFR, which is a transmembrane protein with cytoplasmic kinase activity, transduces important growth factor signaling from the extracellular environment to the interior of the cell (25). EGFR is expressed in $>60 \%$ of NSCLCs and it has emerged as an important therapeutic target in the treatment of various types of tumor (26). Furthermore, it has been reported that NSCLC patients with EGFR mutations exhibit a better response to EGFR-tyrosine kinase inhibitor treatment, as compared with those without EGFR mutations (40).

The results of this study demonstrated that the level of EGFR was inversely correlated with that of miR-143 in NSCLC cells, suggesting that EGRF may be a downstream target of miR-143. Furthermore, miR-143-mediated suppression of EGFR may be a potential mechanism underlying the miR-143-mediated inhibition of NSCLC growth. The effects of inhibiting EGFR expression in HEK293 cells were similar to those observed for the overexpression of miR-143 in A549 NSCLC cells. In previous studies, upregulated EGFR expression was inversely associated with the levels of miR-143 in NSCLC tissues (41-45). miRs reduce the expression level of target genes by binding to mRNA; the mRNA may be degraded or its translation by the ribosome may be suppressed. $(46,47)$. Therefore, in the present study, the downregulated mRNA and protein expression levels of EGFR in NSCLC cells transfected with miR-143 may have been the result of miR-143-mediated downregulation of EGFR mRNA. The results of the present study suggested that miR-143 suppressed the growth, metastasis and invasion of NSCLC cell lines by downregulating the expression of EGFR.

In conclusion, the present study demonstrated that miR-143 was downregulated in NSCLC patient tissues and NSCLC cell lines. The overexpression of miR-143 in NSCLC cells was able to suppress tumor growth, potentially by inhibiting EGFR expression. The results of the present study provided some novel ideas for the future treatment of NSCLC.

\section{References}

1. Jemal A, Bray F, Center MM, Ferlay J, Ward E and Forman D: Global cancer statistics. CA Cancer J Clin 61: 69-90, 2011.

2. Youlden DR, Cramb SM and Baade PD: The international epidemiology of lung cancer: Geographical distribution and secular trends. J Thorac Oncol 3: 819-831, 2008.

3. Globocan 2002: Cancer incidence, mortality and prevalence worldwide. International Agency for Research on Cancer. http://www-dep.iarc.fr/. Accessed January 17, 2008.

4. Xu W, Yang G, Xu Y, Zhang Q, Fu Q, Yu J, Yu M, Zhao W, Yang Z, $\mathrm{Hu} \mathrm{F}$, et al: The possibility of traditional chinese medicine as maintenance therapy for advanced nonsmall cell lung cancer. Evid Based Complement Alternat Med 2014: 278917, 2014.

5. Zarogoulidis K, Zarogoulidis P, Darwiche K, Boutsikou E, Machairiotis N, Tsakiridis K, Katsikogiannis N, Kougioumtzi I, Karapantzos I, Huang H and Spyratos D: Treatment of non-small cell lung cancer (NSCLC). J Thora Dis Suppl 4: S389-S396, 2013.

6. Janku F, Stewart DJ and Kurzrock R: Targeted therapy in nonsmall-cell lung cancer - is it becoming a reality? Nat Rev Clin Oncol 7: 401-414, 2010

7. Toloza EM, Harpole L, Detterbeck F and McCrory DC: Invasive staging of non-small cell lung cancer: A review of the current evidence. Chest 123 (1 Suppl): 157S-166S, 2003.

8. Stone E, Allen HA, Saghaie T, Abbott A, Daniel R, Mead RS, Kohonen-Corish M, Plit M and Morgan L: High proportion of rare and compound epidermal growth factor receptor mutations in an Australian population of non-squamous non-small-cell lung cancer. Intern Med J 44: 1188-1192, 2014.
9. Zhou JJ, Zheng S, Sun LF and Zheng L: MicroRNA regulation network in colorectal cancer metastasis. World J Biol Chem 5: 301-307, 2014.

10. Ning B, Gao L, Liu RH, Liu Y, Zhang NS and Chen ZY: MicroRNAs in spinal cord injury: Potential roles and therapeutic implications. Int J Biol Sci 10: 997-1006, 2014.

11. Rebane A, Runnel T, Aab A, Maslovskaja J, Rückert B, Zimmermann M, Plaas M, Kärner J, Treis A, Pihlap M, et al: MicroRNA-146a alleviates chronic skin inflammation in atopic dermatitis through suppression of innate immune responses in keratinocytes. J Allergy Clin Immunol 134: 836-847, 2014.

12. Wu HH, Lin WC and Tsai KW: Advances in molecular biomarkers for gastric cancer: MiRNAs as emerging novel cancer markers. Expert Rev Mol Med 16: e1, 2014.

13. Schmidt Y, Simunovic F, Strassburg S, Pfeifer D, Stark GB and Finkenzeller G: miR-126 regulates platelet-derived growth factor receptor- $\alpha$ expression and migration of primary human osteoblasts. Biol Chem 396: 61-71, 2015.

14. Nagpal N and Kulshreshtha R: MiR-191: An emerging player in disease biology. Front Genet 5: 99, 2014.

15. Ibrahim SA, Hassan H and Gotte M: MicroRNA-dependent targeting of the extracellular matrix as a mechanism of regulating cell behavior. Biochim Biophys Acta 1840: 2609-2620, 2014.

16. Orang AV and Barzegari A: MicroRNAs in colorectal cancer: From diagnosis to targeted therapy. Asian Pac J Cancer Prev 15: 6989-6999, 2014.

17. Adams BD, Kasinski AL and Slack FJ: Aberrant regulation and function of microRNAs in cancer. Curr Biol 24: R762-R776, 2014.

18. Huang J, Zhang SY, Gao YM, Liu YF, Liu YB, Zhao ZG and Yang K: MicroRNAs as oncogenes or tumour suppressors in oesophageal cancer: Potential biomarkers and therapeutic targets. Cell Prolif 47: 277-286, 2014.

19. Xu B, Niu X, Zhang X, Tao J, Wu D, Wang Z, Li P, Zhang W, $\mathrm{Wu} \mathrm{H}$, Feng $\mathrm{N}$, et al: miR-143 decreases prostate cancer cells proliferation and migration and enhances their sensitivity to docetaxel through suppression of KRAS. Mol Cell Biochem 350: 207-213, 2011.

20. Yu S, Zhang C, Dong FS and Zhang YM: miR-99a suppresses the metastasis of human non-small cell lung cancer cells by targeting AKT1 signaling pathway. J Cell Biochem 116: 268-276, 2015.

21. Fernandez S, Risolino M, Mandia N, Talotta F, Soini Y, Incoronato M, Condorelli G, Banfi S and Verde P: miR-340 inhibits tumor cell proliferation and induces apoptosis by targeting multiple negative regulators of p27 in non-small cell lung cancer. Oncogene 34: 3240-3250, 2014.

22. Zhao X, Liu D, Gong W, Zhao G, Liu L, Yang L and Hou Y: The toll-like receptor 3 ligand, poly(I:C), improves immunosuppressive function and therapeutic effect of mesenchymal stem cells on sepsis via inhibiting MiR-143. Stem Cells 32: 521-533, 2014.

23. Momeni M, Reza MM, Zainodini N, Hassanshahi G and Arababadi MK: MiR-143 induces expression of AIM2 and ASC in Jurkat cell line. Iran J Immunol 10: 103-109, 2013.

24. Zeng XL, Zhang SY, Zheng JF, Yuan H and Wang Y: Altered miR-143 and miR-150 expressions in peripheral blood mononuclear cells for diagnosis of non-small cell lung cancer. Chin Med J (Engl) 126: 4510-4516, 2013.

25. Herbst RS: Review of epidermal growth factor receptor biology. Int J Radiat Oncol Biol Phys 59: S21-S26, 2004.

26. Lu Y, Wang Y, Zhang M, Liu L, Li F, Zhang J, Ye M, Zhao H, Zhao J, Yan B, et al: HER2-siRNA delivered by EGFR-specific single chain antibody inhibits NSCLC cell proliferation and tumor growth. Oncotarget, 2016.

27. Weiss GJ1, Bemis LT, Nakajima E, Sugita M, Birks DK, Robinson WA, Varella-Garcia M, Bunn PA Jr, Haney J, Helfrich BA, et al: EGFR regulation by microRNA in lung cancer: Correlation with clinical response and survival to gefitinib and EGFR expression in cell lines. Ann Oncol 19: 1053-1059, 2008.

28. Livak KJ and Schmittgen TD: Analysis of relative gene expression data using real-time quantitative PCR and the 2(-Delta Delta C(T)) Method. Methods 25: 402-408, 2001.

29. Lu J, Getz G, Miska EA, Alvarez-Saavedra E, Lamb J, Peck D, Sweet-Cordero A, Ebert BL, Mak RH, Ferrando AA, et al: MicroRNA expression profiles classify human cancers. Nature 435: 834-838, 2005

30. Calin GA and Croce CM: MicroRNA signatures in human cancers. Nat Rev Cancer 6: 857-866, 2006. 
31. Phuah NH and Nagoor NH: Regulation of microRNAs by natural agents: New strategies in cancer therapies. Biomed Res Int 2014: 804510, 2014

32. Bartel D P: MicroRNAs: Genomics, biogenesis, mechanism, and function. Cell 116: 281-297, 2004.

33. Cai $\mathrm{Y}, \mathrm{Yu} \mathrm{X}, \mathrm{Hu} \mathrm{S}$ and $\mathrm{Yu} \mathrm{J}$ : A brief review on the mechanisms of miRNA regulation. Genomics Proteomics Bioinformatics 7: 147-154, 2009.

34. Garajova I, Le Large TY, Frampton AE, Rolfo C, Voortman J and Giovannetti E: Molecular mechanisms underlying the role of microRNAs in the chemoresistance of pancreatic cancer. Biomed Res Int 2014: 678401, 2014.

35. Wu XL, Cheng B, Li PY, Huang HJ, Zhao Q, Dan ZL, Tian DA and Zhang P: MicroRNA-143 suppresses gastric cancer cell growth and induces apoptosis by targeting COX-2. World J Gastroenterol 19: 7758-7765, 2013.

36. Ferreira AC, Robaina MC, Rezende LM, Severino $P$ and Klumb CE: Histone deacetylase inhibitor prevents cell growth in Burkitt's lymphoma by regulating PI3K/Akt pathways and leads to upregulation of miR-143, miR-145 and miR-101. Ann Hematol 93: 983-993, 2014.

37. Kopp F, Schnoedt M, Haase R, Wagner E, Roidl A and Ogris M: De-targeting by miR-143 decreases unwanted transgene expression in non-tumorigenic cells. Gene Ther 20: 1104-1109, 2013.

38. Ng EK, Li R, Shin VY, Siu JM, Ma ES and Kwong A: MicroRNA-143 is downregulated in breast cancer and regulates DNA methyltransferases $3 \mathrm{~A}$ in breast cancer cells. Tumour Biol 35: 2591-2598, 2014

39. Blumensatt M, Greulich S, Herzfeld De Wiza D, Mueller H, Maxhera B, Rabelink MJ, Hoeben RC, Akhyari P, Al-Hasani H, Ruige JB, et al: Activin A impairs insulin action in cardiomyocytes via up-regulation of miR-143. Cardiovasc Res 100: 201-210, 2013.
40. Yang Y,Zhang B,Li R, Liu B and Wang L: EGFR-tyrosine kinase inhibitor treatment in a patient with advanced non-small cell lung cancer and concurrent exon 19 and 21 EGFR mutations: A case report and review of the literature. Oncol Lett 11: 3546-3550, 2016.

41. Zhu L, Shi C, Ji C, Xu G, Chen L, Yang L, Fu Z, Cui X, Lu Y and Guo X: FFAs and adipokine-mediated regulation of hsa-miR-143 expression in human adipocytes. Mol Biol Rep 40: 5669-5675, 2013.

42. Wang Q, Cai J, Wang J, Xiong C and Zhao J: MiR-143 inhibits EGFR-signaling-dependent osteosarcoma invasion. Tumour Biol 35: 12743-12748, 2014.

43. Lu J, Xue L, Jin M and Lyu N: Expression profiling of metastasis-related microRNAs in early esophageal squamous cell carcinoma. Zhonghua Bing Li Xue Za Zhi 43: 313-317, 2014 (In Chinese)

44. Mekenkamp LJ, Tol J, Dijkstra JR, de Krijger I, Vink-Börger ME, van Vliet $S$, Teerenstra S, Kamping E, Verwiel E, Koopman M, et al: Beyond KRAS mutation status: Influence of KRAS copy number status and microRNAs on clinical outcome to cetuximab in metastatic colorectal cancer patients. BMC Cancer 12: 292, 2012.

45. da Cunha Santos G, Shepherd FA and Tsao MS: EGFR mutations and lung cancer. Annu Rev Pathol 6: 49-69, 2011.

46. Fabian M R, Sonenberg N and Filipowicz W: Regulation of mRNA translation and stability by microRNAs. Annual Rev Biochem 79: 351-379, 2010.

47. Esquela-Kerscher A and Slack FJ: Oncomirs - microRNAs with a role in cancer. Nat Rev Cancer 6: 259-269, 2006. 